\title{
POTENSI BEBERAPA LARUTAN ORGANIK DALAM MENDUKUNG PRODUKSI BAWANG MERAH (Allium ascalonicum)
}

\author{
Milawati Lalla ${ }^{1}$, Suwandi Said ${ }^{2}$ \\ ${ }^{1}$ Dosen Fakultas Pertanian Universitas Ichsan Gorontalo \\ 2Penyuluh Pertanian Kabupaten Bone Bolango \\ E-Mail: ade_emharla@ymail.com ; suwandisaid@yahoo.com
}

\begin{abstract}
ABSTRAK
Potensi Beberapa Larutan Organik Dalam Mendukung Produksi Bawang Merah (Allium ascalonicum).

Bawang merah merupakan salah satu jenis tanaman yang banyak digunakan sebagai bumbu masakan dan tidak dapat digantikan dengan jenis tanaman lainnya sehingga dibutuhkan setiap waktu. Untuk itu perlu peningkatan produksi dengan memperhatikan kesehatan produk tanaman dengan menggunakan bahan organik. Tujuan penelitian adalah untuk mendapatkan salah satu jenis larutan organik yang menghasilkan produksi bawang merah tertinggi dan mengetahui potensi produksi masing-masing larutan organik yang diberikan. Penelitian dilaksanakan di Kebun Percontohan Balai Penyuluhan Pertanian Bulango Timur pada bulan Januari-April 2020. Penelitian dilaksanakan dalam bentuk Rancangan Acak Kelompok yang terdiri atas 8 perlakuan termasuk kontrol yaitu tanpa penggunaan larutan organik, POC, MOL Nasi, MOL Pisang, ZPT Bawang Merah, ZPT Tauge, PGPR Akar Bambu, dan PGPR Akar Rumput Gajah. Diulang sebanyak 3 kali dengan ukuran plot $1 \mathrm{~m} \times 1 \mathrm{~m}$. Parameter yang diamati adalah bobot segar dan bobot kering umbi bawang merah. Hasil penelitian menunjukkan bahwa bobot segar tertinggi diperoleh dari perlakuan ZPT Bawang Merah (14,22 ton ha $\left.{ }^{-1}\right)$ dan MOL Pisang (14,06 ton ha $\left.{ }^{-1}\right)$. Bobot kering umbi tertinggi dihasilkan dari perlakuan MOL Pisang $\left(9,93\right.$ ton $\left.\mathrm{ha}^{-1}\right)$ dan ZPT Bawang Merah $\left(9,87\right.$ ton ha $\left.{ }^{-1}\right)$.
\end{abstract}

Kata Kunci : Mikroorganisme Lokal, Umbi Kering, Umbi Segar

\section{ABSTRACT}

The Potential of Some Organic Liquids in Supporting the Production of Shallots.

Shallot are one type of plant that is widely used as a spice in cooking and cannot be replaced with other types of plants so it is needed every time. The research objective was to obtain one type of organic solution that produced the highest production of shallots and to calculate the potential production of each given organic solution. The research was conducted at the Kebun Percontohan Balai Penyuluhan Pertanian Bulango Timur in January-April 2020. The research was conducted in the form of Randomized Bloc design consisting of 8 treatments including control i.e. without the use of organic solvents, POC, MOL Rice, MOL Banana, ZPT shallot, ZPT Tauge, PGPR Root Bamboo and PGPR Elephan Grass Root. Repeated 3 times with a plot size $1 \mathrm{~m} \times 1 \mathrm{~m}$. The observed parameters are the weights of fresh and dry weights of shallot. The results showed that the highest fresh weight was obtained from the treatment of ZPT red union 14,22 ton $\left.\mathrm{ha}^{-1}\right)$ and MOL banana (14,06 ton $\left.\mathrm{ha}^{-1}\right)$. The highest dry weight of tubers was obtained from the MOL treatment of banana (9,93 ton $\left.\mathrm{ha}^{-1}\right)$ and ZPT shallot $\left(9,87\right.$ ton $\left.^{\mathrm{ha}} \mathrm{a}^{-1}\right)$.

Keywords : Dry Tubers, Fresh Tubers, Local Microorganism

\section{PENDAHULUAN}

Bawang merupakan salah satu komoditi sayuran umbi yang banyak digunakan sebagai bumbu dalam berbagai jenis masakan sebagai pemberi cita rasa. Beberapa jenis bawang yang cukup populer yaitu bawang merah, bawang putih, bawang bombay dan bawang daun. Namun bawang merah banyak dibutuhkan karena hampir semua jenis masakan menggunakan bawang merah. Bawang merah mengandung minyak atsiri yang menimbulkan aroma khas dan memberikan cita rasa yang gurih. Pemanfaatan bawang merah bukan hanya sebagai bumbu masakan namun sebagai 
bawang goreng menjadikan prospek tanaman bawang merah semakin besar.

Bawang merah dapat dijadikan sebagai obat beberapa jenis penyakit (Rahayu,E., \& Berlian, 2004). Bawang merah megandung antiseptik dan senyawa alliin sehingga dapat digunakan sebagai obat. Senyawa alliin akan diubah menjadi asam piruvat, ammonia dan allisin sebagai anti mikroba yang bersifat bakterisida (Ardi, 2018).

Meskipun bawang merah bukan termasuk tanaman asli Indonesia namun penyebaran tanaman ini merata di seluruh wilayah nusantara. Bahkan beberapa daerah di Indonesia menjadi sentra penanaman bawang merah yaitu Brebes, Bima dan beberapa daerah lainnya bahkan di Gorontalo sudah mulai dikembangkan beberapa varietas bawang merah.

Varietas bauji merupakan salah satu varietas bawang daun dataran rendah yang tahan terhadap penyakit fusarium dan ulat grayak. Peningkatan produktivitas perlu diupayakan dengan kultur teknis salah satunya dengan pemanfaatan berbagai bahan organik sebagai sumber nutrisi bagi tanaman (Surat keputusan menteri pertanian, 2000). Peningkatan produksi dapat dilakukan dengan penggunaan bahan organik yang ramah lingkungan dengan memanfaatkan bahan yang tersedia atau yang tidak terpakai. Pemanfaatan bahan organik untuk pembuatan pupuk organik cair (POC), mikroorganisme lokal (MOL), zat pengatur tumbuh (ZPT) dan plant growth propotion rhyzobacteria (PGPR).

Pupuk organik menurut (Permentan No. 01 tahun 2019 tentang Pendaftara Pupuk Organik, Pupuk hayati dan Pembenah Tanah, 2019), adalah pupuk yang berasal dari tumbuhan mati, kotoran hewan atau bagian hewan atau limbah organik lainnya yang telah melalui proses rekayasa, berbentuk padat atau cair, dapat diperkaya dengan bahan mineral atau mikroba yang bermanfaat untuk meningkatkan kandungan hara dan bahan organik tanah serta memperbaiki sifat fisik, kimia dan biologi tanah. Mengandung hara makro dan mikro esensial serta bahan organik (Djufry, 2013). Pupuk organik cair memiliki keunggulan lebih mudah diserap unsur hara yang terkandung di dalamnya dibandingkan pupuk yang berbentuk padat (Leovini, 2012).

Mikroorganisme lokal adalah larutan hasil fermentasi dari berbagai bahan organik yang diperoleh dari lingkungan sekitar. Dapat berperan sebagai pengurai, menghindarkan tanaman dari infeksi penyakit dan berpotensi sebagai fungisida hayati. Mikroorganisme lokal dapat menjadi penunjang kesuburan tanah karena mengandung hara makro dan mikro (Fitriani, 2015). Mengandung mikroorganisme yang berpotensi sebagai perombak bahan organik, perangsang pertumbuhan, dan agen pengendali hama dan penyakit tanaman (Handayani; S.H, Yunus, 2015). Pemanfaatan MOL dapat menjaga keseimbangan alam, ramah lingkungan dan biaya lebih murah (Fitriani, 2015). Mikroorganisme lokal terdiri atas beberapa jenis sesuai dengan bahan dasarnya yaitu MOL nasi basi, MOL pepaya busuk dan lain-lain (Julita, 2013).

Zat pengatur tumbuh (ZPT) merupakan senyawa organik yang aktif dalam konsentrasi rendah yang dapat merangsang, menghambat atau merubah pertumbuhan dan perkembangan tanaman(Rajiman, 2018). Zat pengatur tumbuh pada dasarnya terdapat dalam tanaman yang disebut dengan ZPT endogen namun dapat juga diberikan ZPT eksogen (Kurniati, Sudartini, \& Hidayat, 2017).

PGPR merupakan kelompok bakteri menguntungkan yang secara aktif 
mengkolonisasi rhyzosfer. PGPR dapat berperan sebagai biofertilizer, biostimulan dan bioprotektan (Khoiratun, Shofiah, \& Tyasmoro, 2018). Aplikasi PGPR meningkatkan daya kecambah benih, merangsang pertumbuhan akar lateral, adventif, akar primer, menghasilkan hormon IAA (Cahyani, Putrayani, Hasrullah, Ersyan, 2017).

Penggunaan bahan organik tersebut berpotensi untuk mendukung pertumbuhan dan produksi tanaman sehingga dapat menggantikan bahan kimia sintetik. Bawang merah merupakan produk hortikultura yang pemanfaatannya dalam keadaan segar sehingga perlu dikembangkan secara alami untuk menghindari residu bahan kimia yang terkandung di dalamnya. Tujuan dari penelitian ini adalah mendapatkan jenis larutan organik yang memberikan hasil terbaik pada bawang merah dan mengetahui potensi produksi masing-masing larutan organik yang diberikan.

\section{METODE PENELITIAN}

\subsection{Waktu dan Tempat}

Penelitian dilaksanakan di kebun percontohan Badan Penyuluhan Pertanian Kec. Bulango Timur Kab. Bone Bolango Provinsi Gorontalo. Berlangsung pada bulan Januari sampai April 2020.

\subsection{Bahan dan Alat}

Bahan yang digunakan dalam penelitian adalah umbi bawang merah varietas Bauji dan berbagai macam bahan organik sebagai bahan pembuatan larutan nutrisi yaitu :

1. POC ; krokot, daun gamal, daun lamtoro, molase

2. MOL Nasi Basi : nasi basi, air cucian beras, molase

3. MOL Pisang Busuk : pisang busuk, air cucian beras, molase
4. ZPT Rebung Bambu : bonggol pisang, air kelapa, molase

5. ZPT Tauge : tauge, air kelapa, molase

6. PGPR akar bambu : akar bambu, air, terasi, dedak, molase

7. PGPR akar rumput gajah : akar rumput gajah, air, terasi, dedak, molase

Alat yang digunakan dalam penelitian adalah ember, pisau, jerigen, saringan, alat menumbuk, timbangan, parang dan gelas ukur.

\subsection{Rancangan Penelitian}

Penelitian dilaksanakan dalam bentuk eksperimen lapangan yang disusun berdasarkan Rancangan Acak Kelompok (RAK). Terdiri atas 8 perlakuan dan diulang sebanyak 3 kali sehingga terdapat 24 plot percobaan yang berukuran $1 \mathrm{~m}^{2}$. Perlakuan terdiri atas :
A. Kontrol
B. POC Krokot
C. MOL Nasi
D. MOL Pisang
E. ZPT Rebung
F. ZPT Tauge
G. PGPR Akar Bambu
H. PGPR Akar Rumput Gajah

\subsection{Pelaksanaan Penelitian}

\section{Pembuatan Larutan Organik}

Penelitian diawali dengan
membuat larutan organik dan
difermentasi selama 14 hari. Jenis bahan
dan komposisi bahan setiap perlakuan
berbeda.

\section{Persiapan Lahan dan Penanaman}

Lahan yang akan digunakan dibajak dan digemburkan. Setelah itu dibuat plot dengan ukuran $1 \mathrm{~m}^{2}$, jarak antar plot $\pm 25 \mathrm{~cm}$ dengan tinggi $\pm 30 \mathrm{~cm}$. 
Sebelum ditanami, plot disiran dengan air. Umbi bawang yang akan ditanam diiris bagian atas (tempat munculnya daun). Ditanam dengan jarak tanam 20 $\mathrm{cm}$ x $20 \mathrm{~cm}$

\section{Aplikasi Larutan Organik}

Aplikasi larutan dilakukan setiap minggu selama 6 kali pada saat tanaman berumur 21 HST hingga 56 HST. Sebelum larutan diaplikasi pada tanaman, diencerkan $100 \mathrm{ml} /$ liter air. Aplikasi dilakukan dengan menyiramkan ke bagian akar tanaman.

\section{Pemeliharaan Tanaman}

Penyiraman dilakukan pada sore hari, pengendalian hama dilakukan dengan cara mekanik. Hama yang muncul selama penelitian adalah belalang dan dikendalikan dengan cara menangkap.

\subsection{Pengamatan}

Parameter yang diamati adalah produksi tanaman saat panen (jumlah umbi setiap rumpun, bobot per umbi, bobot umbi per rumpun) dan bobot umbi setelah umbi dikeringanginkan selama 1 bulan. Panen dilakukan pada umur 70 HST dengan mencabut keseluruhan bagian tanaman.

\subsection{Analisis Data}

Data yang diperoleh dianalisis dengan menggunakan Analisis Sidik Ragam dalam model matematis :

$$
\mathrm{Y}=\mu+\tau+\varepsilon
$$

Hasil yang berpengaruh nyata diuji dengan menggunakan BNT $5 \%$.

\section{HASIL DAN PEMBAHASAN}

\section{Bobot Segar Panen}

Pengamatan bobot regar
dilakukan setelah panen dengan
menimbang umbi beserta daun segar
sehingga bobot segar dari data ini
merupakan bobot keseluruhan tanaman.

Setelah ditimbang, dikeringanginkan selama 1 bulan untuk pengambilan data bobot umbi. Hasil analisis sidik ragam menunjukkan bahwa pemberian bahan organik berpengaruh nyata terhadap jumlah dan bobot umbi bawang merah. Rata-rata hasil pengamatan dan hasil Uji BNT disajikan pada Tabel 1.

Tabel 1. Jumlah dan Bobot Umbi Segar Bawang Merah dari Berbagai Larutan Organik

\begin{tabular}{|c|c|c|c|c|c|}
\hline Perlakuan & $\begin{array}{l}\text { Jumlah } \\
\text { Umbi } \\
\text { (Siung) }\end{array}$ & $\begin{array}{l}\text { Bobot Umbi } \\
\text { Per Rumpun } \\
\quad \text { (Gram) }\end{array}$ & $\begin{array}{l}\text { Bobot Per } \\
\text { Umbi } \\
\text { (Gram) }\end{array}$ & $\begin{array}{c}\text { Bobot Umbi } \\
\text { Per Plot } \\
\text { (Gram) }\end{array}$ & $\begin{array}{l}\text { Bobot Umbi } \\
\text { Per Hektar } \\
\text { (Ton) }\end{array}$ \\
\hline Kontrol & $5,79 \mathrm{a}$ & $27,94 \mathrm{~b}$ & 4,84 & $893,97 \mathrm{a}$ & $8,94 \mathrm{a}$ \\
\hline PGPR A.Bambu & $5,65 \mathrm{a}$ & $26,36 \mathrm{a}$ & 4,67 & $843,41 \mathrm{a}$ & $8,43 \mathrm{a}$ \\
\hline POC Krokot & $6,08 \mathrm{ab}$ & $29,75 b$ & 4,94 & $952,11 \mathrm{a}$ & $9,52 \mathrm{a}$ \\
\hline PGPR A.R.Gajah & $5,50 \mathrm{a}$ & $30,13 b$ & 5,42 & $964,05 \mathrm{a}$ & $9,64 \mathrm{a}$ \\
\hline
\end{tabular}




\begin{tabular}{|c|c|c|c|c|c|}
\hline MOL Nasi & $6,46 a b$ & $37,00 \mathrm{~b}$ & 5,74 & $1184,00 \mathrm{a}$ & $11,84 \mathrm{a}$ \\
\hline ZPT Tauge & $6,19 \mathrm{ab}$ & $34,88 \mathrm{~b}$ & 5,72 & $1116,05 \mathrm{a}$ & $11,16 \mathrm{a}$ \\
\hline MOL Pisang & $6,86 \mathrm{~b}$ & $43,94 \mathrm{c}$ & 6,42 & $1406,08 \mathrm{~b}$ & $14,06 \mathrm{~b}$ \\
\hline ZPT B.Merah & $7,17 \mathrm{~b}$ & $44,44 \mathrm{c}$ & 6,23 & $1422,08 \mathrm{~b}$ & $14,22 \mathrm{~b}$ \\
\hline
\end{tabular}

Keterangan : Angka yang diikuti dengan huruf yang sama tidak berbeda nyata

Tabel 1 menunjukkan bahwa bobot bawang merah tertinggi dihasilkan dari perlakuan ZPT bawang merah dan MOL pisang dan berbeda nyata dengan perlakuan lainnya. Perlakuan tersebut menghasilkan bobot per umbi tertinggi namun tidak berbeda nyata dengan semua perlakuan. Hasil tertinggi yang diperoleh merupakan kontribusi dari berbagai kandungan bahan organik yang terdapat di dalam larutan MOL dan ZPT yang diberikan.

ZPT bawang merah mengandung hormon auksin dan allithiamin yang dapat memacu pertumbuhan akar, pemanjangan sel dan memperlancar metabolisme pada jaringan tumbuhan (Sofwan, D, Triatmoko, \& Iftitah, 2018). Auksin berperan dalam pengembangan sel akar, fototropisme, apikal dominan dan respirasi (Kurniati et al., 2017). Umbi bawang merah juga mengandung hormon endogen yang merangsang pembelahan sel pada jaringan meristem tanaman (Muslimah, Jalil, Hadianto, Sarwanidas, \& Hasan, 2015). Mikroorganisme lokal dapat digunakan sebagai pupuk karena unsur hara yang terkandung di dalam MOL dapat berperan dalam pertumbuhan tanaman. MOL buah-buahan mengandung $\mathrm{N}$ dan $\mathrm{P}$ yang dapat meningkatkan pertumbuhan vegetatif pada tanaman (Parawansa \& Ramli, 2014).

Potensi hasil umbi bawang merah yang dihasilkan dari pemberian MOL pisang dan ZPT bawang merah lebih tinggi dan berbeda nyata dari larutan organik yang lainnya.

\section{Bobot Kering}

Data bobot kering umbi diperoleh dengan menimbang umbi yang telah dikeringanginkan selama 1 bulan. Berdasarkan hasil analisis sidik ragam menunjukkan bahwa pemberian larutan organik berpengaruh nyata seperti yang disajikan pada Tabel 2.

Tabel 2. Bobot Umbi Kering Bawang Merah dari Beberapa Larutan Organik

\begin{tabular}{lrrr}
\hline \multicolumn{1}{c}{ Perlakuan } & $\begin{array}{c}\text { Bobot Umbi Per Rumpun } \\
(\text { Gram })\end{array}$ & $\begin{array}{c}\text { Bobot Umbi Per Plot } \\
(\text { Gram })\end{array}$ & $\begin{array}{c}\text { Bobot Umbi Per Hektar } \\
\text { (Ton) }\end{array}$ \\
\hline Kontrol & $17,48 \mathrm{a}$ & $559,25 \mathrm{a}$ & $5,59 \mathrm{a}$ \\
\hline PGPR A.Bambu & $17,81 \mathrm{a}$ & $570,03 \mathrm{a}$ & $5,70 \mathrm{a}$ \\
\hline POC Krokot & $19,86 \mathrm{a}$ & $635,41 \mathrm{a}$ & $6,35 \mathrm{a}$ \\
\hline ZPT Tauge & $20,54 \mathrm{a}$ & $657,39 \mathrm{a}$ & $6,57 \mathrm{a}$ \\
\hline MOL Nasi & $23,62 \mathrm{ab}$ & $755,95 \mathrm{ab}$ & $7,56 \mathrm{ab}$ \\
\hline PGPR A.R.Gajah & $23,64 \mathrm{ab}$ & $756,59 \mathrm{ab}$ & $7,57 \mathrm{ab}$ \\
\hline
\end{tabular}




\begin{tabular}{cccr}
\hline ZPT B.Merah & $30,84 \mathrm{~b}$ & $986,77 \mathrm{~b}$ & $9,87 \mathrm{~b}$ \\
\hline MOL Pisang & $31,02 \mathrm{~b}$ & $992,75 \mathrm{~b}$ & $9,93 \mathrm{~b}$ \\
\hline BNT 5\% & $\mathbf{7 , 6 9}$ & $\mathbf{2 4 6 , 2 3}$ & $\mathbf{2 , 4 6}$ \\
\hline
\end{tabular}

Keterangan: Angka yang diikuti dengan huruf yang sama berarti tidak berbeda nyata

Tabel 2 menunjukkan bahwa MOL pisang dan ZPT bawang merah menghasilkan bobot umbi kering bawang merah tertinggi dari perlakuan lainnya. Dengan potensi hasil 9 ton $\mathrm{ha}^{-1}$ umbi kering. Hasil tersebut menandakan bahwa penggunaan ekstrak bawang merah sebagai ZPT dan MOL Pisang berpotensi menghasilkan produksi umbi bawang merah yang lebih tinggi.

Larutan MOL mengandung unsur hara untuk mendukung pertumbuhan tanaman dan mikroba yang dapat memperbaiki struktur tanah serta memperbaiki sifat biologi tanah. MOL dapat berfungsi sebagai pupuk organik yang dapat memperbaiki konsidi tanah dalam hal ketersediaan unsur hara yang diperlukan untuk pertumbuhan tanaman. Mikroba tanah yang berperan dalam proses dekomposisi larutan organik yang diberikan sehingga dapat membantu dalam penyediaan hara pada tanaman (Suhastyo \& Raditya, 2019).

ZPT mempengaruhi proses fisiologi tanaman. Respon tumbuhan terhadap ZPT yang diberikan tergantung dari jenis ZPT yang diberikan (Kurniati, Hodiyah, 2018). Kandungan auksin dan sitokinin pada ekstrak bawang merah dapat memacu pertumbuhan tanaman (Muslimah et al., 2015). Senyawa allithiamin pada bawang merah dapat memperlancar metabolisme pada jaringan tanaman (Sofwan et al., 2018). Pemberian ZPT bawang merah dan MOL pisang berpotensi menghasilkan bobot umbi bawang merah yang lebih tinggi.

\section{KESIMPULAN}

Berdasarkan hasil yang telah diperoleh dapat disimpulkan bahwa MOL pisang dan ZPT bawang merah memberikan hasil bobot umbi tertinggi dibandingkan dengan larutan organik lainnya. Potensi hasil umbi segar dari ZPT Bawang Merah (14,22 ton $\left.\mathrm{ha}^{-1}\right)$ dan MOL Pisang (14,06 ton ha $\left.{ }^{-1}\right)$. Potensi hasil umbi kering dari perlakuan MOL Pisang (9,93 ton $\left.\mathrm{ha}^{-1}\right)$ dan ZPT Bawang Merah (9,87 ton ha $\left.{ }^{-1}\right)$.

\section{UCAPAN TERIMA KASIH}

Terima kasih kepada Balai Penyuluhan Pertanian (BPP) Kec. Bulango Timur Kab. Bone Bolango atas perkenaannya untuk meminjamkan lahan dan semua fasilitas selama masa penelitian.

\section{DAFTAR PUSTAKA}

Ardi, E. (2018). Bawang merah teknik budidaya dan peluang usahanya. Yogyakarta: Trans Idea Publishing.

Cahyani, Putrayani, Hasrullah, Ersyan, A. \& J. (2017). Teknologi formulasi rhizobakteria berbasis bahan lokal dalam menunjang bioindustri pertanian berkelanjutan. Hasanuddin Student Journal, 1(1), 16-21. 
Djufry, F. \& R. (2013). Uji efektivitas pupuk organik Hi-Tech 19 pada tanaman sawi hijau. 408-416. Makassar: Balai Pengkajian Teknologi Sul-Sel.

Fitriani, M. S. ; E.; J. (2015). Uji efektivitas beberapa mikroorganisme lokal terhadap pertumbuhan dan hasil tanaman sawi hijau (Brassica juncea L.). Jurnal Penelitian Universitas Jambi Seri Sains, 17(2), 68-74.

Handayani ; S.H, Yunus, A. \& S. (2015). Uji kualitas pupuk organik dari berbagai macam mikroorganisme lokal (MOL). El Vivo, 3(1), 54-60.

Julita, S. ; G. H. \& M. (2013). Pengaruh pemberian mikroorganisme lokal (MOL) nasi dan hormon tanaman unggul terhadap pertumbuhan dan produksi tanaman cabai ( Capsicum annum L .). Dinamika Pertanian, XXVIII(3), 167-174.

Khoiratun, D., Shofiah, R., \& Tyasmoro, S. Y. (2018). Aplikasi PGPR (plant growth promoting rhizobacteria) dan pupuk kotoran kambing pada pertumbuhan dan hasil bawang merah (Allium ascalonicum L.) varietas manjung. Produksi Tanaman, 6(1), 76-82.

Kurniati, Hodiyah, H. \& N. (2018). Respons labu madu (Cucurbita moshata) terhadap zat pengatur tumbuh alami dengan berbagai dosis. Agricultural Research \& Technology Journal, 2(1), 16-21.

Kurniati, F., Sudartini, T. \&, \& Hidayat, D. (2017). Aplikasi berbagai bahan ZPT alami untuk meningkatkan pertumbuhan bibit kemiri sunan (Reutealis trisperma (Blanco) Airy Shaw). Jurnal Agro, 4(1), 40-49. https://doi.org/10.15575/1307
Muslimah, Y., Jalil, M., Hadianto, W., Sarwanidas, T., \& Hasan, A. (2015). Pengaruh konsentrasi ekstrak bawang merah dan media tanam terhadap stek mucuna (Mucunabracteata) The Effect of Onion Extract and Media TowardsGrowth Cuttings on Mucunabracteata. Agrotek Lestari, 1(1), 47-54.

Parawansa \& Ramli. (2014). Mikroorganisme lokal (MOL) buah pisang dan pepaya terhadap pertumbuhan tanaman ubi jalar (Ipomoea batatas). Agrisistem, 10(1), 10-15.

Permentan No. 01 tahun 2019 tentang Pendaftara Pupuk Organik, Pupuk hayati dan Pembenah Tanah. (2019).

Rahayu,E., \& Berlian, N. (2004). Bawang merah. Jakarta:Indonesia: Penebar Swadaya.

Rajiman, R. (2018). Pengaruh zat pengatur tumbuh (ZPT) alami terhadap hasil dan kualitas bawang merah. Prosiding Seminar Nasional Fakultas Pertanian UNS, 2(1), A-327-335. Retrieved from http://jurnal.fp.uns.ac.id/index.php/s emnas/article/view/1068/839

Sofwan, N., D, O. F. K., Triatmoko, A. H., \& Iftitah, S. N. (2018). Optimasi ZPT (Zat Pengatur Tumbuhan) alami ekstrak bawang merah (Allium cepa fa. ascalonicum) sebagai pemacu pertumbuhan akar stek tanaman buah tin (Ficus carica). VIGOR: Jurnal Ilmu Pertanian Tropika Dan Subtropika, 3(2), 4648. Retrieved from http://jurnal.untidar.ac.id/index.php/ vigor/article/view/1000/658

Suhastyo, A. A., \& Raditya, F. T. (2019). 
Respon pertumbuhan dan hasil Sawi pagoda (Brassica narinosa) terhadap pemberian MOL daun kelor. Agrotech Research Journal, 3(June), 56-60.

https://doi.org/10.20961/agrotechres j.v3i1.29064
Surat keputusan menteri pertanian. (2000). Pelepasan Varietas Bawang Merah Bauji Sebagai Varietas Unggul Dengan Nama Bauji (p. No.65/Kpts/TP.240/2/2000). No.65/Kpts/TP.240/2/2000. 